\title{
ОБ ОПЫТЕ ПРИМЕНЕНИЯ ИНФОРМАЦИОННО- КОММУНИКАЦИОННЫХ МЕТОДОВ КОНТРОЛЯ В РАМКАХ ДИСТАНЦИОННОГО ОБУЧЕНИЯ ИНОСТРАННОМУ ЯЗЫКУ В НЕЯЗЫКОВОМ ВУЗЕ
}

\section{ON THE EXPERIENCE OF USING INFORMATION AND COMMUNICATION METHODS OF CONTROL IN THE FRAMEWORK OF DISTANCE LEARNING OF A FOREIGN LANGUAGE IN A NON-LINGUISTIC UNIVERSITY}

\section{Ogorodov \\ S. Bakaeva \\ E. Samorodova \\ I. Belyaeva}

Summary: In this paper, its authors analyze the experience of using various distance control methods used by teachers during the forced reference to distance learning, discuss their effectiveness and application possibilities. The exercise of control affects the not only the methodologists and language teachers works, since in addition to creating special control methods - online tests, surveys, control works, the question arises of the technical equipment of educational institutions with the necessary equipment. The joint and cohesive work of specialists of higher educational institutions in the creation of modern educational platforms and programs, new technologies in solving existing problems, is a necessary condition for achieving a successful result.

Keywords: distance control methods, online tests, distance education, information and communication methods.
Огородов Михаил Константинович

К.фрилол.н., ФГАОУ ВО «МосковскИй государственный институт международных отношений (университет) Министерства иностранных дел Российской Федерации» Mike_box@inbox.ru

Бакаева София Андреевна

К.фрилол.Н., ФГАОУ ВО «МосковскИй государственный институт международных отношений (университет) Министерства иностранных дел Российской Федерации» sophiebakaeva@gmail.com

Самородова Екатерина Александровна к.ю.н., ФГАОУВО «Московский государственный институт международных отношений (университет) Министерства иностранных дел Российской Федерации» Samorodova.ekaterina.78@mail.ru

Беляева Ирина Георгиевна

к.филол.н., ФГАОУ ВО «Московский государственный институт международных отношений (университет) Министерства иностранных дел Российской Федерации» irinatimakova@mail.ru

Аннотация: В данной работе ее авторы анализируют опыт использования различных дистанционных приёмов контроля, задействованных преподавателями во время вынужденного перехода на дистанционное обучение, обсуждают их эффективность и возможности применения. Осуществление контроля затрагивает работу не только методистов и преподавателей языка, поскольку помимо создания специальных методик контроля - онлайн тестов, опросов, контрольных работ, встает вопрос о техническом оснащении учебных учреждений необходимым оборудованием. Совместная и сплочённая работа специалистов высших учебных заведений в создании современных образовательных платформ и программ, новых технологий в решении сложившихся проблем, представляет собой необходимое условие для достижения успешного результата.

Ключевые слова: дистанционные приемы контроля, онлайн тесты, дистанционное образование, информационно-коммуникационные методы.

дистанционных приёмов контроля, анализируются конкретные задания и методики проверок, использовавшиеся преподавателями во время вынужденного перехода на дистанционное обучение, делается вывод об их эффективности, возможностях применения и перспективах практического развития.

Ситуация, сложившаяся в сфере образования весной 2020-го года, подтолкнула преподавателей, работавших доселе в аудиториях, к тому, чтобы экстренно искать 
новые приемлемые и эффективные методы контроля в системе дистанционного обучения '. Несмотря на изменившуюся парадигму осуществления образовательных услуг в онлайн-формате, когда преподавателям пришлось стихийно перейти на удалённую форму работы со студентами, роль контрольных мероприятий попрежнему осталась одной из самых важных. Во-первых, контроль (промежуточный и финальный), сохранившийся в том или ином виде при переходе на дистант, выполнял дисциплинарную функцию, маркируя для студентов значимость и стабильность образовательных процессов, которые вынужденно перешли в интернет-пространство. Во-вторых, контроль знаний (онлайн-тесты, письменные и устные зачетные работы, презентация проектов, экзаменационные конференции и так далее) и его результаты в конечном итоге показали, насколько эффективными были попытки реализации различных методик дистанционного преподавания в период пандемии 2020-го года. В данной статье мы предприняли попытку описать практический опыт проведения контроля знаний по иностранному языку (французский и немецкий языки) среди студентов 1-3 курсов в неязыковом ВУЗе (МГИМО (у) МИД РФ), а также определить трудности, с которыми столкнулись преподаватели на этом этапе.

Преподавание иностранного языка в неязыковом ВУЗе предполагает строгие критерии работы и определения её итогов: учащийся за установленный отрезок времени должен овладеть компетенциями, которые позволят ему применить знание иностранного языка, как профессионального инструмента, на практике. В частности, формально в конце первого курса уровень владения французским языком у студента, который изучает этот язык как основной, должен достигать А2, в конце второго курса - В1, в конце третьего курса - В2-С1 и так далее. В ходе занятий учащийся должен развить и усовершенствовать лингвистические навыки, которые дадут ему возможность успешно взаимодействовать с зарубежными партнёрами, участвовать в межкультурной коммуникации, максимально интегрировать изученный иностранный язык в профессиональную сферу своей жизни. И этот долгий процесс всестороннего обучения иностранному языку предположительно должен постоянно контролироваться преподавателем: с помощью текущих и итоговых форм контроля знаний.

Если мы говорим о преподавании иностранных языков, то формы этого контроля могут быть, безусловно, вариативными, однако, их главной целью будет являться выявление уровня освоения пройденного материала у всех студентов.[1] Так, студенты с первого по третий курс, изучающие иностранный язык как основной, в рамках аудиторной работы в течение семестра обязаны пройти текущие и итоговые тестирования. Под текущими тестированиями, к выбору которых преподаватель подходит индивидуально в зависимости от специфики той или иной группы, подразумеваются: диктанты, письменные блиц-опросы, тематические тесты, самостоятельные работы, упражнения по спряжению глаголов на время, спонтанные устные ответы на оценку и так далее. Эти задания носят ненормированный характер, однако, обязаны соответствовать пройденному материалу, иметь чёткую структуру и конкретное назначение. Итоговые тестирования, как правило, проводятся в конце семестра, а также модульно: по завершению определенного блока учебного материала. Они являются обязательными, а их форма строго регламентируется методистом (старшим преподавателем / руководителем курса). В данный контроль входит: 1) письменное тестирование (контрольная работа); 2) проверка компетенций: контроль понимания речи на слух и анализ услышанной информации; контроль работы с текстом; контроль письменной речи на основе сформированных лексико-грамматических навыков; 3) устная форма зачета / экзамена. Безусловно, этот список трансформируется и расширяется с учетом потребностей каждого конкретного направления обучения, курса и факультета.

И если многочисленные методы и приёмы контроля качества обучения иностранному языку в рамках очных аудиторных занятий широко описаны российскими исследователями (см. Готлиб Р.А., Матиенко А.В., Кирина Л.В., Цой Е.Д., Попкова О.А., Редькина С.Д., Дроздова А.В и многие другие), то формы контроля в рамках тотального перехода на дистанционное обучение еще предстоит исследовать, проанализировать и описать.

В первую очередь, нам представляется необходимым отметить то, что важнейшей проблемой выбора методики контролирования результатов обучения стал человеческий (психологический) фактор. Нестандартные условия работы, новые технические возможности взаимодействия с преподавателем и другими студентами, изолированность от привычной университетской среды, к сожалению, выявили ряд трудностей, связанных, в частности, с невозможностью объективного контроля знаний. Опыт, приобретенный за несколько месяцев дистанционной работы со студентами, поставил под вопрос прозрачность процесса обучения и усвоения материала. Как следствие, это затруднило выбор единой формы итогового контроля по иностранному языку, а также по многим другим дисциплинам.

С подобными трудностями, например, столкнулись и наши французские коллеги, которые, оставив формы контроля неизменными, попытались справиться с проблемой «жульничества» на экзамене более глобальными

1 В данной статье мы будем использовать как синонимы термины «дистанционное обучение», «дистанционное образование», «дистант», «удалённое обучение», «онлайн-обучение». 
методами. Так, Европейский университетский центр Лотарингии предложил ввести в практику использование дорогостоящей системы дистанционного (телевизионного) наблюдения (télésurveillance), которая призвана записывать видео и звук с компьютера каждого тестируемого студента ${ }^{2}$. Подобной программой воспользовался и Университет Ренн І $^{3}$ : студенты были обязаны скачать приложение, которое получало доступ к их веб-камере и автоматически делало снимок экрана раз в 3 секунды. Университет Кан-Нормандия ${ }^{4}$ использовал персональную программу Managexam, которая предполагала несколько степеней защиты (вход в аккаунт по скану паспорта, автоматические фотографии каждые несколько секунд и так далее). Бельгийский университет города Намюр 5 порекомендовал преподавателям не пользоваться для проведения экзаменов приложениями Google, Youtube, Facebook, Messenger WhatsApp и Skype, предложив более защищенные сервисы Teams и Blackboard. А вот Льежский университет, напротив, отказался от технических приёмов, предложив студентам просто подписать «хартию честной игры» ${ }^{6}$

Однако, даже в тех реалиях, когда особые методы дистанционного наблюдения не применялись, проводить контрольные мероприятия в тех или иных формах представлялось необходимым. Перечислим некоторые из них.

Так, промежуточный и итоговый контроль, осуществляемый при помощи системы Online Test Pad, показал её несостоятельность ввиду технического несовершенства: большое количество правильных ответов системой не воспринимаются. Напротив, тестирование на платформе MOODLE зарекомендовало себя как надёжный способ промежуточного и итогового контролей. Минусом, присущим различным формам контроля на данных online платформах, стало отсутствие идентификации студентов, что не давало гарантий выполнения работы конкретным учащимся. Текущий контроль обучающихся, как правило, осуществлялся в устной форме во время конференций в вебинаре или ZOOM. Ежедневно оценивалась работа студентов на уроке, которая складывалась из их ответов за разнообразные виды деятельности в устной форме и домашние письменные задания. Существовало несколько типов проверки письменных работ: студенты присылали материалы на почту в формате Word c последующей их проверкой преподавателем при помощи программы «Рецензирование». Либо же проверка осуществлялась через системy Google Classroom. Отличия в подходах в оценивании письменных работ в дистанционном и очном формате не было, и степень объективности оценки, как и при проверке письменных работ в процессе очного посещения студентами университета, была довольно низкой. Поэтому вопрос о системе оценивания письменных работ, как при удалённом, так и при очном обучении остаётся открытым. И при одной, и при другой форме обучения письменные задания тогда становятся более эффективными (как средство тренировки навыков учащихся), когда они вообще не подлежат оцениванию. Существует мнение, что отсутствие у студентов страха получить низкий бал за выполненную домашнюю работу стимулирует их к самостоятельному выполнению заданий. Опыт показал, что письменные работы, которые подлежали оценке со стороны преподавателя, всегда выполнялись лучше, чем работы, которые им проверялись, но не оценивались. Таким образом, можно выдвинуть предположение о том, что наличие большого количества ошибок косвенно свидетельствует о большой степени вероятности самостоятельного выполнения письменных заданий студентами.

Эффективная форма очного контроля под условным названием «Презентация» (представление индивидуального или группового «проекта») имеет низкую эффективность как форма контроля в удалённом режиме, так как по большей части студенты «прочитывают» своё выступление. Таким образом, основные цели подобного педагогического приёма - развитие устных компетенций, навыков публичного выступления, повышение познавательной мотивации и ответственности за результаты, более высокая эффективность усвоения темы [2] - не достигаются, а трансформируются в художественное чтение подготовленного текста. Истинные знания в таком формате можно лишь проверить, спонтанно задавая дополнительные вопросы. Именно спонтанность задаваемых вопросов способствует наибольшей объективности выставляемых оценок за устные виды деятельности при обучении на расстоянии.

Еще одним экспериментальным способом контроля стал тест с автоматической проверкой в Google-формах, считающийся многими практикующими преподавателями достоверным и объективным.[3] Однако, он не в полной мере оправдал ожидания ввиду некоторых технологических несовершенств (каждый тест требовал повторной итоговой проверки преподавателем, а значит, лишался автоматичности), а также ограниченности типов грамматических и лексических заданий по иностранному языку, которые можно оформить в виде теста.

\footnotetext{
2 https://www.francebleu.fr/infos/education/universite-triche-generalisee-aux-examens-a-distance-ou-organisation-futee-158875460

$3 \mathrm{https}: / /$ www.bfmtv.com/tech/vie-numerique/examens-a-distance-contre-la-triche-les-universites-tentees-par-la-telesurveillancedes-etudiants_AN-202005100046.html

4 https://www.letudiant.fr/examen/coronavirus-comment-etes-vous-surveille-lors-des-examens-a-distance.html

5 https://www.rtbf.be/info/regions/detail_a-l-universite-les-examens-de-premiere-session-auront-lieu-a-distance?id=10486463

6 https://www.rtbf.be/info/regions/detail_a---universite-les-examens-de-premiere-session-auront-lieu-a-distance?id=10486463
} 
Для проверки лексики наиболее корректным видом задания и дидактическим инструментом оказалось «сочинение по облаку слов», которое требовало от студента самостоятельной творческой работы и практически исключало возможность списывания. Кроме того, подобный вид деятельности способствовал развитию структурного, критического, пространственного мышления, а также аналитических способностей учащихся, необходимых для полноценного изучения иностранного языка [4]. Можно в подобные тематические облака включить слова, не относящиеся напрямую к данной теме. Подобная хитрость поможет понять преподавателю способность студентов применить новую лексику, выбрать правильный контекст. «Облака» выводятся на экран в режиме онлайн конференции . Студенту дается время на подготовку не более 5-10 минут. Задание могут выполнять сразу несколько студентов.

Как пример можно привести такое упражнение.

Faites une histoire en employant le vocabulaire appris/npuдумайте историю используя выученные слова

(soleil, bateau, ami, renard, chien, rôti, accablant, courageux, été, paysage, chasse, ensemble, aéronef)

Альтернативным приёмом контроля лексики, вписавшимся в рамки дистанционного обучения, оказалось задание на работу с синонимами - составление логических цепочек. Этот вид контроля, как, впрочем, и все остальные, требует большой подготовительной работы преподавателя, который составляет блоки заданий либо в формате презентации, либо на любой онлайн-платформе, позволяющей создать подобный тест.

Как было отмечено выше, наиболее эффективным методом оценивания знаний представляется устный контроль во время видео-семинара. Например, успешно проявил себя такой метод проверки лексики как перевод с русского языка на иностранный, при котором в формате онлайн-презентации каждое предложение выводится индивидуально на экран, студенту даётся минута на обдумывание, после чего фраза с экрана исчезает. Затем был опробован метод «мигающего теста» в режиме реального времени, когда у опрашиваемого студента есть не более 5 секунд, чтобы выбрать и озвучить правильный вариант ответа. Подобный вид контроля оправдал себя на занятиях по политическому переводу и юридическому переводу (двустороннего) для студентов старших курсов факультета международных отношений и международного права. Также в качестве примера контроля перевода с листа можно привести такое задание.

На экране представлена таблица с двусторонним переводом с текстом, расположенного в шахматном порядке, студент видит только ту часть, которую нужно перевести (в том случае, если технически сложно создать упражнение с мигающим текстом). Подобное расположение текста на странице помогает обучающему сконцентрироваться.

Traduisez les textes ci-dessous.

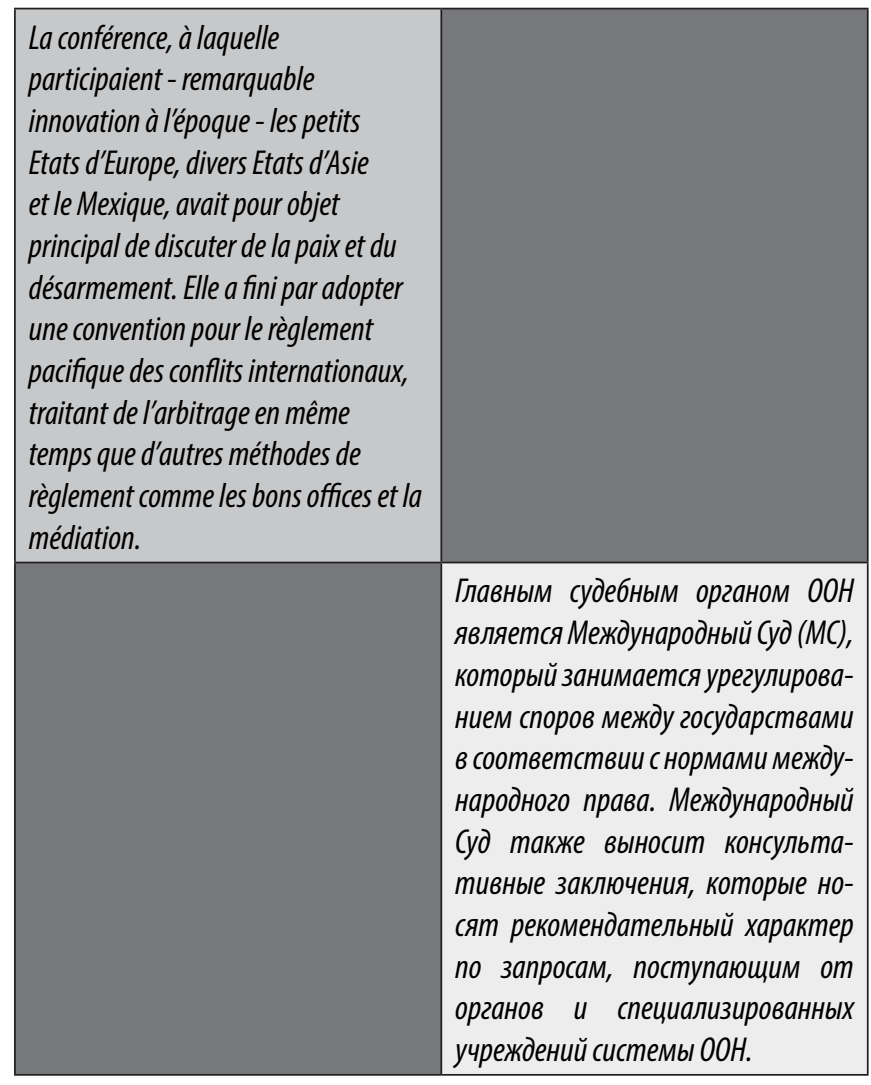

Дистанционное образование, ставшее определённой альтернативой современному очному образованию, имеет свои преимущества и недостатки. Новые технологии, позволяющие организацию образовательного процесса в удаленном доступе и дающие возможность каждому желающему человеку получить высшее образование, независимо от географического расположения вуза, неоспоримо являются огромным достижением научного прогресса. Но вместе с тем, перед преподавателем возникают серьезные задачи обеспечения должного контроля знаний, полученных в результате такой работы. Приведенный выше анализ способов осуществления контроля помогает понять основные сложности, с которыми сталкиваются организаторы учебного процесса, а также обозначить вектор дальнейшего движения на пути выработки оптимальных средств, подходов и методов оценивания знаний в удалённом доступе. Помимо создания специальных методик контроля - онлайн тестов, опросов, контрольных работ, встает вопрос о техническом оснащении учебных учреждений необходимым оборудованием. И здесь уже речь идет о работе не только методистов и преподавателей языка. Совместная и сплочённая работа специалистов высших учебных заведений в создании современных образовательных платформ и программ, новых технологий в решении сложившихся проблем, представляет собой необходимое условие для достижения успешного результата. 


\section{ЛИТЕРАТУРА}

1. Батунова И. В. Тестирование как один из наиболее эффективных методов контроля при обучении студентов неязыковых специальностей иностранному языку / И.В. Батунова // Международный научно-исследовательский журнал. — 2017. — № 05 (59) Часть 2. — C. 8 - 10. doi: 10.23670/IRJ.2017.59.005]

2. Дашкина А.И., Фёдорова А.Я. Синергетический эффект парной и групповой работы студентов при подготовке полимедийной презентации // Вопросы методики преподавания в вузе. 2013. №2 (16). URL: https://cyberleninka.ru/article/n/sinergeticheskiy-effekt-parnoy-i-gruppovoy-raboty-studentov-pripodgotovke-polimediynoy-prezentatsii (дата обращения: 12.07.2020).

3. Ламонина Л.В., Смирнова О.Б. Использование возможностей информационно-образовательной среды вуза для оперативного контроля результатов обучения // Электронный научно-методический журнал Омского ГАУ. 2017. №S3. URL: https://cyberleninka.ru/article/n/ispolzovanie-vozmozhnosteyinformatsionno-obrazovatelnoy-sredy-vuza-dlya-operativnogo-kontrolya-rezultatov-obucheniya (дата обращения: 14.07.2020).

4. Сапух Т.В. Современные средства формирования лексических навыков учащихся на уроках английского языка (на примере облака слов) // АНИ: педагогика и психология. 2018. №3 (24). С.212].

() Огородов Михаил Константинович (Mike_box@inbox.ru), Бакаева София Андреевна (sophiebakaeva@gmail.com), Самородова Екатерина Александровна (Samorodova.ekaterina.78@mail.ru), Беляева Ирина Георгиевна (irinatimakova@mail.ru).

Журнал «Современная наука: актуальные проблемы теории и практики»

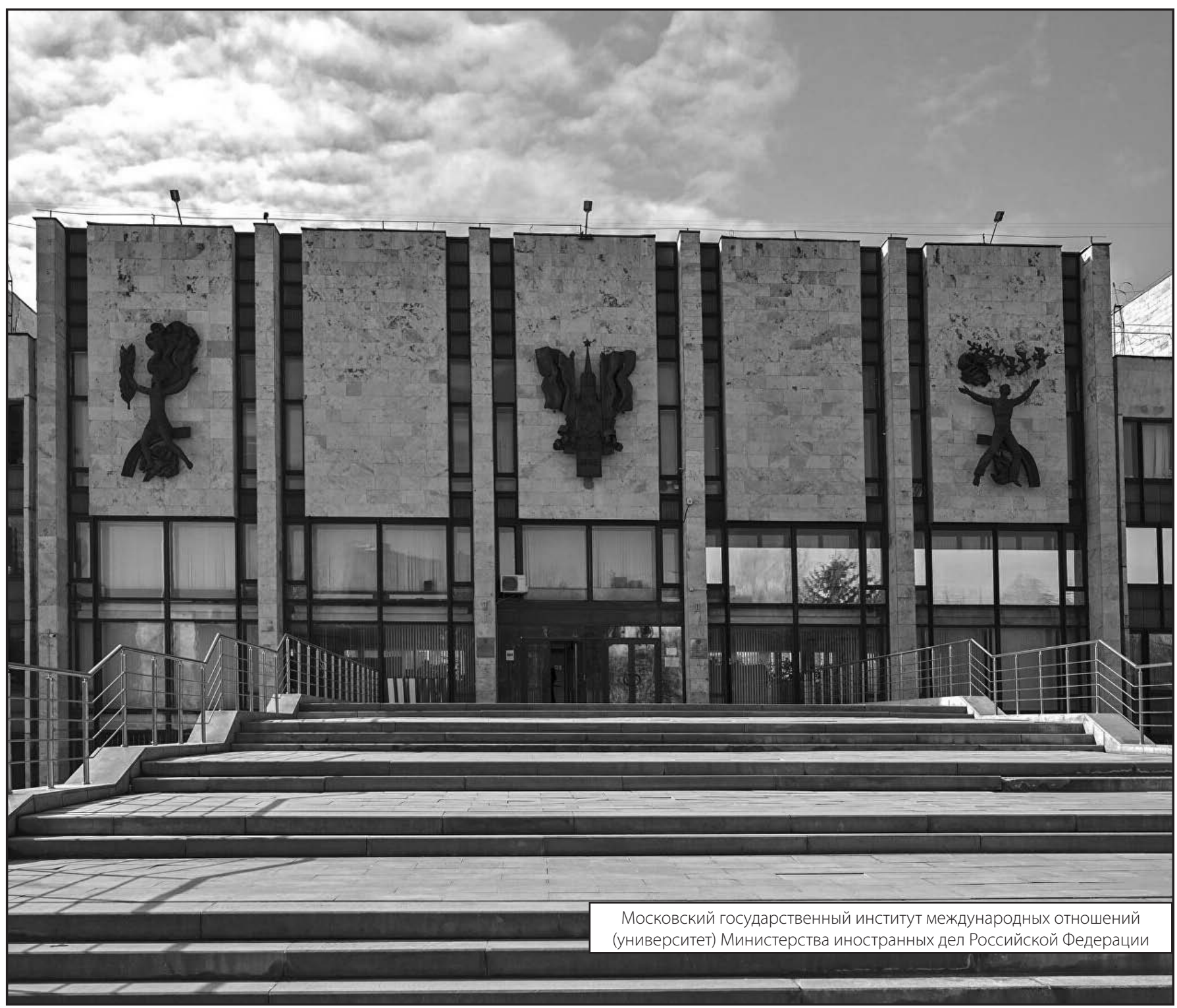

